\title{
PENGARUH AIR PDAM, LAUT, COMBERAN PADA PROSES CURING TERHADAP KUAT TEKAN BETON Fc 14,53 Mpa
}

\author{
Richo Dwi Saputra ${ }^{1}$, Rasio Hepiyanto ${ }^{2}$ \\ 1) Program Studi Teknik Sipil Universitas Islam Lamongan \\ 2) Prodi Fakultas Teknik Dosen Teknik Sipil Universitas Islam Lamongan \\ email : richodwisaputra2205@gmail.com,waringinmegah_rasio@yahoo.com
}

\begin{abstract}
Concrete is a mixture of concrete forming materials, namely: fine aggregate, coarse aggregate, cement, and water. Each concrete construction always be able to show its function, ie strength and endurance during the planned life. Therefore, in this research concrete treatment is known to increase the concrete but also need to know how long the concrete treatment is good Only requires water from the loss of water experienced. Thus the research is conducted to find out how much the influence of curing process uses sea water, PDAM sewage toward to the strength of concrete press. This research was conducted with the use of 3 types of water that is water PDAM, sea water, sewage. Cylindrical tests specimen with diameter $15 \mathrm{~cm}$ and height $30 \mathrm{~cm}$. Each sample is made of 3 specimens by the age of 7 days. The value of compressive strength in PDAM water, seawater, sewage successively at the age of 7 days is 13,522 MPa, 8,759 MPa, 10,296 $M P a$. The value of compressive strength of Water PDAM at 7 days has increased compared to the compressive strength value of seawater and sewage, while the value of compressive strength of seawater has decreased compared to the rising sewage. So it can be concluded that the value of the highest compressive strength is water PDAM at the age of 7 days.
\end{abstract}

\section{Keywords: PDAM Water, Seawater, sewage, Curing, Concrete, Compressive Strength.}

\section{PENDAHULUAN}

Beton merupakan campuran materialmaterial pembentuk beton, yaitu: agregat halus, agregat kasar, semen, dan air dengan perbandingan tertentu dengan atau tanpa bahan tambahan. Beton sebagai salah satu bagian kontruksi yang penting, dimana pemakaian dan kegunaannya yang begitu luas dan umum. Beton merupakan bahan yang sangat bervariasi, kualitasnya dapat diperoleh dengan berbagai komposisi campuran dan tata cara pembuataannya. Kualitas beton juga sangat ditentukan dari tata cara perawatannya.

Bervariasinya bahan dasar pembentuk beton menyebabkan beton mempunyai beberapa sifat, diantaranya adalah sifat awet daya tahan beton. Perawatan beton merupakan prosedur yang digunakan untuk membantu mempercepat proses hidrasi beton, menjaga kestabilan temperature dan perubahan kelembaban di dalam maupun diluar beton itu sendiri, perawatan beton menjaga beton dalam kondisi kekedapan yang maksimum sampai ruang air pada pasta.

Pada dasarnya setiap kontruksi beton haruslah selalu dapat menampilkan fungsinya, yaitu kekuatan dan daya tahan selama umur yang direncanakan. Dengan demikian beton harus mampu bertahan terhadap proses perusakan yang dapat terjadi. Oleh karena itu pada penelitian ini perawatan beton diketahui akan meningkatkan beton namun perlu diketahui juga berapa lama perawatan beton tersebut yang baik hanya membutuhkan air akibat kehilangan air yang dialami. Seperti apa yang telah dijabarkan didepan, perawatan beton memegang peranan yang sangat penting untuk mewujudkan tercapainya daya tahan beton sesuai dengan yang diinginkan.

Sehingga dengan adanya penelitian ini diharapkan dapat memberikan jawaban mengenai pengaruh air PDAM, air laut, air 
comberan pada proses curing beton terhadap kuat tekan beton f'c 14,53 Mpa yang direncanakan. Adapun penelitian ini mempunyai tujuan untuk mengetahui seberapa besar pengaruh proses curing menggunakan air laut, air PDAM, air comberan terhadap kuat tekan beton.

\section{METODE PENELITIAN Rancangan Penelitian}

Penelitian ini menggunakan metode eksperimen, yaitu penelitian dengan percobaan langsung di laboratorium Universitas Islam Lamongan yang bertujuan untuk menyelidiki pengaruh proses curing terhadap air untuk mengetahui kuat tekan beton.

\section{Lokasi Penelitian dan Waktu Pelaksanaaan}

Untuk melaksanakan kegiatan penelitian ini yaitu pengaruh air kotor, air pdam dan air laut pada proses curing untuk mengetahui kuat tekan beton (f'c 14.53) Mpa dilaksanakan di laboratorium iniversitas islam lamongan. Waktu pelaksanaan untuk melaksanakan penelitian dilakukan pada jangka waktu bulan mei sampai dengan juni.

\section{Teknik Pengumpulan Data}

Pengumpulan data dilakukan untuk memperoleh informasi yang dibutuhkan dalam rangka mencapai tujuan penelitian. Proses pengumpulan data ditentukan oleh variabelvariabel yang ada dalam hipotesis. Pengumpulan data dilakukan terhadap sampel yang telah ditentukan sebelumnya. Data adalah sesuatu yang belum memiliki arti bagi penerimanya dan masih membutuhkan adanya suatu pengolahan. Data bisa memiliki berbagai wujud, mulai dari gambar, suara, huruf, angka, bahasa, simbol, bahkan keadaan. Alat ini harus dipilih sesuai dengan jenis data yang diinginkan dalam penelitian, instrumen penelitian merupakan alat bantu yang dipilih \& digunakan oleh peneliti dalam melakukan kegiatannya untuk mengumpulkan data agar kegiatan tersebut menjadi sistematis.

\section{Sumber Data}

Sumber data terbagi menjadi dua yaitu data primer dan data sekunder. Data primer adalah data yang diperoleh peneliti secara langsung (dari tangan pertama), sementara data sekunder adalah data yang diperoleh peneliti dari sumber yang sudah ada.
1. Data primer merupakan sumber data yang diperoleh secara langsung dari sumber asli atau pihak pertama. Data primer secara khusus dikumpulkan oleh peneliti untuk menjawab pertanyaan riset atau penelitian. Data primer dapat berupa pendapat subjek riset (orang) baik secara individu maupun kelompok, hasil observasi terhadap suatu benda (fisik), kejadian, atau kegiatan, dan hasil pengujian. Manfaat utama dari data primer adalahbahwa unsur-unsur kebohongan tertutup terhadap sumber fenomena.

2. Data sekunder merupakan sumber data yang diperoleh peneliti secara tidak langsung melalui media perantara. Data sekunder pada umumnya berupa bukti, catatan, atau laporan historis yang telah tersusun dalam arsip, baik yang dipublikasikan dan yang tidak dipublikasikan.

\section{Proses Perawatan Beton (Curing)}

Proses curing dilaksanakan dengan cara merendam beton dalam bak yang berisi air sampai waktu pengetesan. Proses perawatan (curing) ini dilakukan sehari atau 24 jam setelah proses pencetakan beton.

Langkah - langkah proses perawatan (curing) :

a) Setelah 24 jam dari proses pencetakan beton, cetakan beton dibuka perlahan lahan dan beton uji silinder beton diambil.

b) Benda uji silinder beton diletakkan dalam suatu bak air, dan dibiarkan sampai sehari sebelum waktu pengetesan untuk dikeluarkan dari bak (pengeringan).

c) Pada waktu pengetesan, benda uji yang telah dikeluarkan dari bak dan mengering ditimbang beratnya. Setelah itu diukur dimensinya.

d) Kemudian benda uji di capping/diratakan dengan larutan belerang pada bidang tidak rata.

e) Permukaan yang di capping dari benda uji diletakkan di atas, dan benda uji siap dites. 


\section{Diagram Alir Peneilitian}

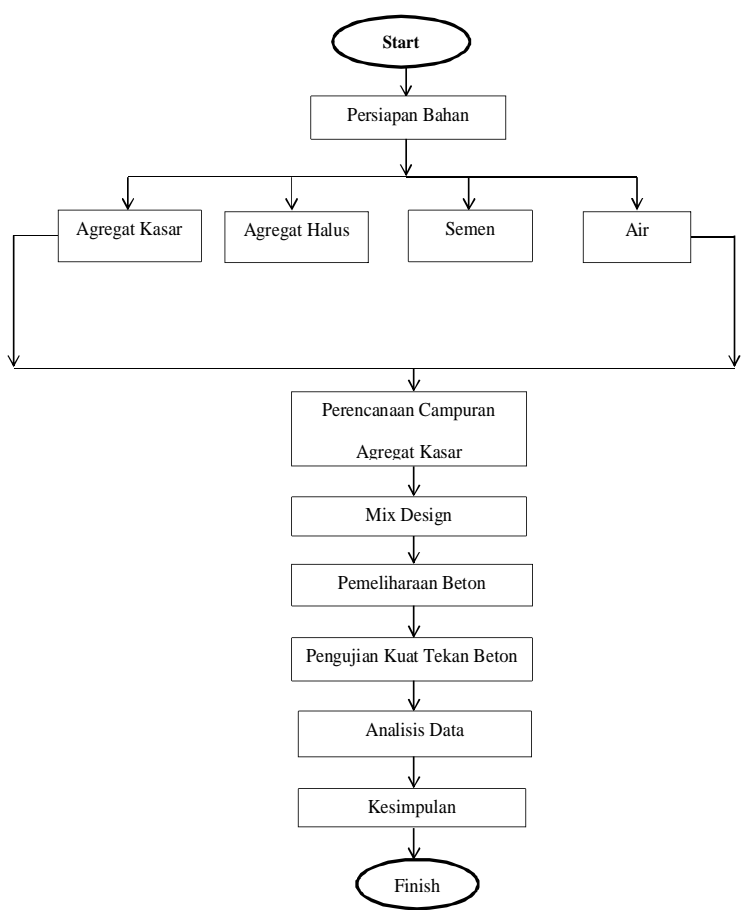

Gambar 1 Diagram Alir Penelitian

\section{HASIL DAN PEMBAAHASAN Proses Perawatan (Curing)}

Proses ini dilakukan setelah pencopotan beton berlangsung dan tentunya setelah pemberian nama bagi masing-masing benda uji yang telah dibuat untuk pengujian berlangsung, untuk proses curing air yang digunakan menggunakan air PDAM. Uji kuat tekan akan di lakukan setelah proses curing berlangsung yaitu 7 hari perendaman.

Untuk perendaman yang perlu diperhatikan untuk menjaga kelambapan beton saat diredam jangan sampai beton kehabisan air saat perendaman itu bisa diakibatkan karena kebocoran tempat perendaman maupun penyusutan air karena beton itu sendiri, dalam hal ini pengecekan air harus dilakukan setiap hari guna menanggulangi masalah ini, pengisian juga perlu dilakukaan agar air tetap terjaga satabil untuk proses perendaman.

\section{Pengujian Kuat Beton}

Pengujian ini dilakukan terhadap beton segar (fresh concrete) yang mewakili campuran beton, bentuk benda uji bisa berwujud silinder ataupun kubus; hasil pengujian ini dapat digunakan dalam pekerjaan :

a. Perencanaan campuran beton;

b. Pengendalian mutu beton pada pelaksanaan pembetonan.

\section{Pengujian Kuat Tekan}

Pelaksanaan pengujian kuat tekan beton harus diikuti beberapa tahapan sebagai berikut:

a. Meletakan benda uji pada mesin tekan secara centris;

b. Menjalankan mesin tekan dengan penambahan beban yang konstan

c. Melakukan pembebanan sampai benda uji menjadi hancur dan catat beban maksimum yang terjadi selama pemeriksaan benda uji.

Tabel 1. Data Tes Kuat Tekan Umur 7 Hari.

\begin{tabular}{|c|c|c|c|c|c|c|c|c|}
\hline $\begin{array}{l}\text { Jenis } \\
\text { beton }\end{array}$ & $\begin{array}{c}\text { Ukuran } \\
(\mathbf{c m})\end{array}$ & $\begin{array}{c}\text { Luas } \\
\text { Penampang } \\
\left(\mathrm{cm}^{2}\right)\end{array}$ & $\begin{array}{l}\text { Umur } \\
\text { (hari) }\end{array}$ & $\begin{array}{c}\text { Volume } \\
\text { Benda } \\
\text { Uji }\left(M^{3}\right)\end{array}$ & $\begin{array}{c}\text { Berat } \\
(\mathrm{kg})\end{array}$ & $\begin{array}{c}\text { Tekanan } \\
\text { Hancur } \\
\text { (kg) }\end{array}$ & $\begin{array}{c}\text { Tegangan } \\
\text { Hancur } \\
\text { sb'I } \\
\left(\mathbf{k g} / \mathrm{cm}^{2}\right) \\
\end{array}$ & $\begin{array}{c}\text { BJ } \\
\text { Beton } \\
\left(\mathbf{k g} / \mathbf{m}^{3}\right)\end{array}$ \\
\hline \multirow{3}{*}{$\begin{array}{c}\text { Air } \\
\text { PDAM }\end{array}$} & F 15-30 & 176.625 & \multirow[t]{3}{*}{7} & 0.005299 & 12.737 & 29000 & 164.19 & 2403.66 \\
\hline & F 15-30 & 176.625 & & 0.005299 & 12.24 & 30000 & 169.85 & 2309.87 \\
\hline & F 15-30 & 176.625 & & 0.005299 & 12.254 & 29000 & 164.19 & 2312.51 \\
\hline \multirow[t]{3}{*}{ Air Laut } & F 15-30 & 176.625 & \multirow[t]{3}{*}{7} & 0.005299 & 11.467 & 20000 & 113.23 & 2307.61 \\
\hline & F 15-30 & 176.625 & & 0.005299 & 11.18 & 18000 & 101.91 & 2327.61 \\
\hline & F 15-30 & 176.625 & & 0.005299 & 11.283 & 19000 & 107.57 & 2301.19 \\
\hline \multirow{3}{*}{$\begin{array}{c}\text { Air } \\
\text { Comberan }\end{array}$} & F 15-30 & 176.625 & \multirow[t]{3}{*}{7} & 0.005299 & 11.932 & 22000 & 124.56 & 2251.75 \\
\hline & F 15-30 & 176.625 & & 0.005299 & 11.048 & 24000 & 135.88 & 2084.92 \\
\hline & F 15-30 & 176.625 & & 0.005299 & 11.728 & 21000 & 118.90 & 2213.25 \\
\hline
\end{tabular}

Sumber: Hasil Penelitian 


\section{Berat Isi Kering Beton Ringan}

Pengujian berat isi kering beton ringan dilakukan pada umur beton 7 hari dengan benda uji silinder. Benda uji mengalami curing selama 7 hari dan dikeringkan udara selama 1 hari kemudian dilakukan pengujian.

Berat isi beton ringan rata-rata yang dihasilkan pada tabel2 memperlihatkan bahwa berat isi kering udara beton yang dihasilkan termasuk dalam kategori berat beton ringan struktural yang disyaratkan SNI 03-3449-2002, yaitu beton yang mempunyai berat isi kering udara antara $2000-2500 \mathrm{~kg} / \mathrm{m} 3$.

\section{Kuat Tekan Beton}

Pengujian kuat tekan beton ini mengacu pada SNI 03-1947-1990 pengujian kuat tekan ini di maksudkan sebagai pegangan dalam pengujian untuk menentukan kuat tekan (compressive strength) beton dengan benda uji berbentuk silinder yang dibuat dan dimatangkan (curing) di laboratorium.

\section{Kuat Tekan Beton Ringan}

Pengujian kuat tekan pada benda uji beton ringan dilakukan pada saat beton berumur 7 hari. Tujuan pengujian kuat tekan beton ringan ini selain untuk mengetahui nilai kekuatan tekan beton juga sebagai pembanding dengan nilai kuat tekanbeton pada pengujian skripsi sebelumnya. Hasil pengujian kuat tekan beton ringan dengan benda uji berbentuk silinder ( 15 $\times 30) \mathrm{cm}$ berjumlah 3 buah dapat dilihat pada tabel berikut ini.

Tabel 2.Pengujian Berat Isi Kering Beton Ringan

\begin{tabular}{cccccc}
\hline Sampel & Berat $(\mathbf{k g})$ & Diameter $(\mathbf{c m})$ & Tinggi $(\mathbf{c m})$ & Volume $\left(\mathbf{m}^{\mathbf{3}}\right)$ & $\begin{array}{c}\text { Berat Isi Kering } \\
\mathbf{( k g} / \mathbf{m 3})\end{array}$ \\
\hline PDAM & 12.737 & 15 & 30 & 0.0053 & 2403.208 \\
\hline PDAM & 12.24 & 15 & 30 & 0.0053 & 2309.434 \\
\hline PDAM & 12.254 & 15 & 30 & 0.0053 & 2312.075 \\
\hline Laut & 11.467 & 15 & 30 & 0.0053 & 2163.585 \\
\hline Laut & 11.18 & 15 & 30 & 0.0053 & 2109.434 \\
\hline Laut & 11.283 & 15 & 30 & 0.0053 & 2128.868 \\
\hline Comberan & 11.932 & 15 & 30 & 0.0053 & 2251.321 \\
\hline Comberan & 11.048 & 15 & 30 & 0.0053 & 2084.528 \\
\hline Comberan & 11.728 & 15 & 30 & 0.0053 & 2212.830 \\
\hline \multicolumn{7}{r}{} & rata-rata & & 2219.476 \\
\hline
\end{tabular}

Sumber: Hasil Perhitungan

Tabel 3 Kuat Tekan Hancur Umur 7 Hari

\begin{tabular}{ccccccccc}
\hline $\begin{array}{c}\text { Kode } \\
\text { Beton }\end{array}$ & $\begin{array}{c}\text { Ukuran } \\
(\mathbf{c m})\end{array}$ & $\begin{array}{c}\text { Luas } \\
\text { Penampang } \\
\left(\mathbf{c m}^{2}\right)\end{array}$ & $\begin{array}{c}\text { Umur } \\
(\text { hari })\end{array}$ & $\begin{array}{c}\text { Berat } \\
(\mathbf{k g})\end{array}$ & $\begin{array}{c}\text { Volume } \\
\text { Cilinder } \\
\text { Beton }\left(\mathbf{m}^{\mathbf{3}}\right)\end{array}$ & $\begin{array}{c}\text { BJ } \\
\text { Beton } \\
\left(\mathbf{k g} / \mathbf{m}^{\mathbf{3}}\right)\end{array}$ & $\begin{array}{c}\text { Tekanan } \\
\text { Hancur } \\
(\mathbf{k g})\end{array}$ & $\begin{array}{c}\text { Hasil Uji } \\
\text { Tekan sb'I } \\
(\mathbf{k g} / \mathbf{c m})\end{array}$ \\
\hline PDAM & F 15-30 & 176.625 & 7 hari & 12.74 & 0.5300 & 24.03 & 29000 & 164.19 \\
\hline PDAM & F 15-30 & 176.625 & 7 hari & 12.24 & 0.5300 & 23.09 & 30000 & 169.85 \\
\hline PDAM & F 15-30 & 176.625 & 7 hari & 12.25 & 0.5300 & 23.12 & 29000 & 164.19 \\
\hline Laut & F 15-30 & 176.625 & 7 hari & 11.47 & 0.5300 & 21.64 & 20000 & 113.23 \\
\hline Laut & F 15-30 & 176.625 & 7 hari & 11.18 & 0.5300 & 21.09 & 18000 & 101.91 \\
\hline Laut & F 15-30 & 176.625 & 7 hari & 11.28 & 0.5300 & 21.29 & 19000 & 107.57 \\
\hline Comberan & F 15-30 & 176.625 & 7 hari & 11.93 & 0.5300 & 22.51 & 22000 & 124.56 \\
\hline Comberan & F 15-30 & 176.625 & 7 hari & 11.05 & 0.5300 & 20.85 & 24000 & 135.88 \\
\hline Comberan & F 15-30 & 176.625 & 7 hari & 11.73 & 0.5300 & 22.13 & 21000 & 118.90 \\
\hline Sumber: & & & & & & & &
\end{tabular}

Sumber: Hasil Perhitungan 
Tabel 4.Kuat Tekan Beton Ringan

\begin{tabular}{cccc}
\hline No & Kode & $\begin{array}{c}\text { Kuat Tekan } \\
\left(\mathrm{kg} / \mathrm{cm}^{2}\right)\end{array}$ & $\begin{array}{c}\text { Rata-rata } \\
\left(\mathrm{kg} / \mathrm{cm}^{2}\right)\end{array}$ \\
\hline 1 & PDAM & 164.19 & \\
\hline 2 & PDAM & 169.85 & 166.077 \\
\hline 3 & PDAM & 164.19 & \\
\hline 4 & Laut & 113.23 & \\
\hline 5 & Laut & 101.91 & 107.573 \\
\hline 6 & Laut & 107.57 & \\
\hline 7 & Comberan & 124.56 & \\
\hline 8 & Comberan & 135.88 & 126.445 \\
\hline 9 & Comberan & 118.90 & \\
\hline
\end{tabular}

Sumber : Hasil Penelitian

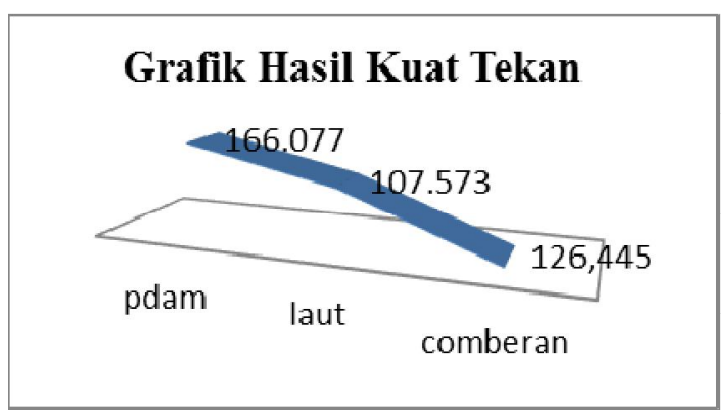

Gambar 2. Grafik Kuat Tekan Beton Ringan

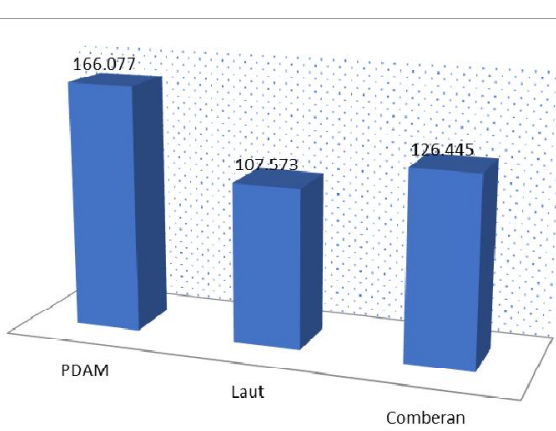

Gambar 3. Bar chat Hasil Kuat Tekan

Dari hasil kuat tekan pada umur 7 hari pada gambar 2 dan gambar 3 dapat diketahui bahwa nilai kuat tekan beton yang menggunakan air PDAM mendekati Beton K 175 (14,53 Mpa), sedangkan yang menggunakan air laut dan air comberan masih jauh mendekati beton K 175 (14,53 Mpa).

Tabel 5. Data Kuat Tekan Hancur Air PDAM Setelah Dikorelasi Umur 7 Hari

\begin{tabular}{cccccccccc}
\hline Kode & $\begin{array}{c}\text { Umur } \\
\text { Tes }\end{array}$ & $\begin{array}{c}\text { Hasil } \\
\text { Tes }\end{array}$ & $\begin{array}{c}\text { Korelasi } \\
\text { Umur }\end{array}$ & $\begin{array}{c}\text { Teg } \\
\text { Silinder }\end{array}$ & $\begin{array}{c}\text { Rata- } \\
\text { rata Tb' }\end{array}$ & $\begin{array}{c}\text { (Tb- } \\
\text { Tb')2 }\end{array}$ & $\begin{array}{c}\text { Teg } \\
\text { Deviasi } \\
\text { Standar }\end{array}$ & $\begin{array}{c}\text { Teg } \\
\text { Karakter } \\
\text { istik (K) }\end{array}$ & $\begin{array}{c}\text { Karakteris } \\
\text { tik (fc') }\end{array}$ \\
\hline PDAM & 7 Hari & 164.19 & 0.65 & 252.60 & 255.50 & 8.42 & 5.03 & 247.26 & 20.522 \\
\hline PDAM & 7 Hari & 169.85 & 0.65 & 261.31 & 255.50 & 33.70 & 5.03 & 247.26 & 20.522 \\
\hline PDAM & 7 Hari & 164.19 & 0.65 & 252.60 & 255.50 & 8.42 & 5.03 & 247.26 & 20.522 \\
\hline
\end{tabular}

Sumber: Hasil Perhitungan

Tabel 6. Data Kuat Tekan Hancur Air Laut Setelah Dikorelasi Umur 7 Hari

\begin{tabular}{cccccccccc}
\hline Kode & $\begin{array}{c}\text { Umur } \\
\text { Test }\end{array}$ & $\begin{array}{c}\text { Hasil } \\
\text { Tes }\end{array}$ & $\begin{array}{c}\text { Koreksi } \\
\text { Umur }\end{array}$ & Silinder & $\begin{array}{c}\text { Teg } \\
\text { Rata- } \\
\text { rata Tb' }\end{array}$ & $\begin{array}{c}\text { (Tb- } \\
\text { Tb')2 }\end{array}$ & $\begin{array}{c}\text { Deviasi } \\
\text { Standar }\end{array}$ & $\begin{array}{c}\text { Karakter } \\
\text { istik (K) }\end{array}$ & $\begin{array}{c}\text { Teg } \\
\text { Karakteri } \\
\text { stik (fc') }\end{array}$ \\
\hline Laut & 7 Hari & 113.23 & 0.65 & 174.20 & 165.49 & 75.82 & 8.71 & 151.21 & 12.551 \\
\hline Laut & 7 Hari & 101.91 & 0.65 & 156.78 & 165.49 & 75.82 & 8.71 & 151.21 & 12.551 \\
\hline Laut & 7 Hari & 107.57 & 0.65 & 165.49 & 165.49 & 0.00 & 8.71 & 151.21 & 12.551 \\
\hline & & & & 496.48 & & 151.65 & & & \\
\hline
\end{tabular}

Sumber: Hasil Perhitungan

Tabel 7. Data Kuat Tekan Hancur Air Comberan Setelah Dikorelasi Umur 7 Hari

\begin{tabular}{cccccccccc}
\hline Kode & $\begin{array}{c}\text { Umur } \\
\text { Test }\end{array}$ & $\begin{array}{c}\text { Hasil } \\
\text { Tes }\end{array}$ & $\begin{array}{c}\text { Koreksi } \\
\text { Umur }\end{array}$ & $\begin{array}{c}\text { Teg } \\
\text { Silinder }\end{array}$ & $\begin{array}{c}\text { Rata- } \\
\text { rata Tb' }\end{array}$ & $\begin{array}{c}\text { (Tb- } \\
\text { Tb')2 }\end{array}$ & $\begin{array}{c}\text { Deviasi } \\
\text { Standar }\end{array}$ & $\begin{array}{c}\text { Teg } \\
\text { Karakter } \\
\text { istik }(\mathbf{K})\end{array}$ & $\begin{array}{c}\text { Teg } \\
\text { Karakteri } \\
\text { stik (fc') }\end{array}$ \\
\hline Comberan & 7 Hari & 124.56 & 0.65 & 80.96 & 82.19 & 1.50 & 5.62 & 72.97 & 76.815 \\
\hline Comberan & 7 Hari & 135.88 & 0.65 & 88.32 & 82.19 & 37.60 & 5.62 & 72.97 & 76.815 \\
\hline Comberan & 7 Hari & 118.90 & 0.65 & 77.29 & 82.19 & 24.06 & 5.62 & 72.97 & 76.815 \\
\hline
\end{tabular}

Sumber: Hasil Perhitungan 


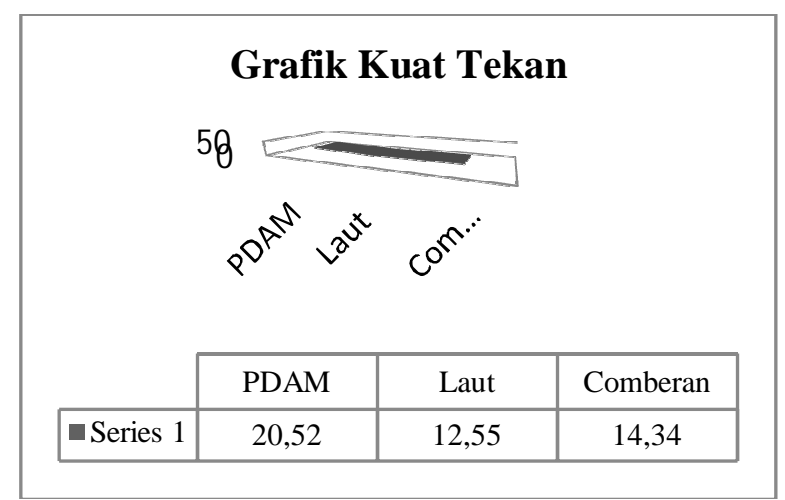

Gambar 4. Grafik Kuat Tekan Hancur

\section{Bar Chat Kuat Tekan}

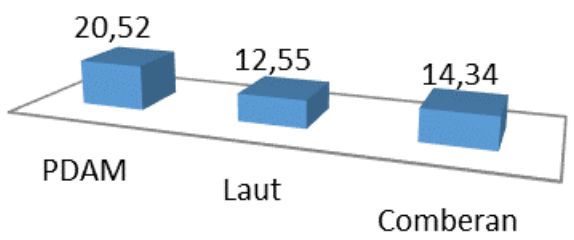

Gambar 5.Bar Chat Kuat Tekan Hancur

Dari hasil kuat tekan hancur yang telah dikorelasi pada umur 7 hari pada gambar 4 dan gambar 5dapat diketahui bahwa beton yang menggunakan air PDAM menghasilkan kuat tekan yang lebih dibandingkan dengan air laut dan air comberan.

\section{KESIMPULAN}

Dari hasil penelitian pada proses curing air PDAM, air laut dan air comberan dapat diambil kesimpulan sebagai berikut :

Pada umur 7 hari untuk nilai kuat tekan maksimum pada air PDAM, air laut, air comberan secara berturut-turut sebesar 13,522MPa, 8,759 MPa, 10,296 MPa. Nilai kuat tekan Air PDAM pada umur 7 hari mengalami kenaikan dibandingkan nilai kuat tekan air laut dan air comberan, sedangkan nilai kuat tekan air laut mengalami penurunan dibandingkan dengan air comberan yang mengalami kenaikan. Sehingga dapat disimpulkan bahwa nilai kuat tekan yang tertinggi berada air PDAM pada umur 7 hari.

\section{Saran}

Dengan adanya hasil penelitian proses curing yang telah saya lakukan diharapkan bagi peneliti lain bisa menyempurnakan penelitian ini lebih baik lagi.

\section{DAFTAR PUSTAKA}

Danang Anwar Fauzi, 2013, Analisa Kuat Tekan Dan Kuat Tarik Beton Dengan Perawatan Dalam Lumpur Dan Air Laut, Naskah Publikasi, Universitas Muhammadiyah Surakarta.

Norman Ray, 2016, Studi Angka Koefisien Korelasi Kuat Tekan Beton Mutu Tinggi Berdasarkan Umur dan Bentuk Benda Uji Standart SNI 03-2844-2002, Jurnal Teknik Sipil, Universitas Widya Kartika Surabaya.

Ristinah Syamsuddin, 2011, Pengaruh Air Laut Pada Perawatan (Curing) Beton Terhadap Kuat Tekan Dan Absorspi Beton Dengan Variasi Faktor Air Semen Dan Durasi Perawatan, Jurnal Rekayasa Sipil Volume 5 No. 2, Universitas Brawijaya Malang.

Rosie Arizki Intan Sari, 2015, Pengaruh Jumlah Semen dan Fas Terhadap Kuat Tekan Beton Dengan Agregat Yang Berasal Dari Sungai, Jurnal Sipil Stastik Vol.3 No.1, Manado.

SNI-7394-2008, Tata Cara Perhitungan Harga Satuan Pekerjaan Beton untuk Kontruksi Bangunan Gedung dan Perumahan.

Ir. Erry Irianto, 1988, Insitut Sains dan Teknologi Nasional Fakultas Teknik Sipil dan Perencanaan Laboratorium Beton, Pedoman Praktikum Beton, Jakarta Selatan. 